\title{
Nova Scotia sets direction on GPS monitoring of patients
}

$\mathrm{N}$ ova Scotia is the first jurisdiction in Canada to officially ban the use of electronic monitoring for forensic mental health patients. The announcement follows a government investigation into the issue following the April 2012 killing of a wellknown gay Halifax activist allegedly by a patient who was absent without leave from the East Coast Forensic Hospital in Dartmouth, Nova Scotia.

"It's a highly emotionally charged issue," says Elaine Gibson, an associate professor with the Health Law Institute at Dalhousie University and coauthor of one of three reports on electronic monitoring prepared for the provincial health department. "People want answers and the family [of the victim] wanted electronic monitoring. It was wise of the government to pause and have this review."

One of the reports looked at the international precedents; another assessed the literature. Gibson and her colleagues explored the legal ramifications of requiring mental health forensic patients to wear GPS tracking bracelets when they are on authorized leave or if they are at risk of flight. Forensic mental health patients are held for two reasons: either they are being assessed for mental competency or have been found not mentally competent to stand trial.

Gibson's report concludes that a legal challenge of the bracelets could well be successful on either human rights grounds or as a violation of the protection afforded by the Canadian Charter of Rights and Freedoms. "Our charter analysis led us to conclude in this case the technology is not worth the downsides."

Those downsides include potentially substantial ill effects on patients, says Ken Scott, director of mental health services with the Department of Health and Wellness in Halifax. "National organizations have expressed concerns around the stigma and further criminalizing mental illness."

Health professionals were also worried that forcing patients to wear a tracking

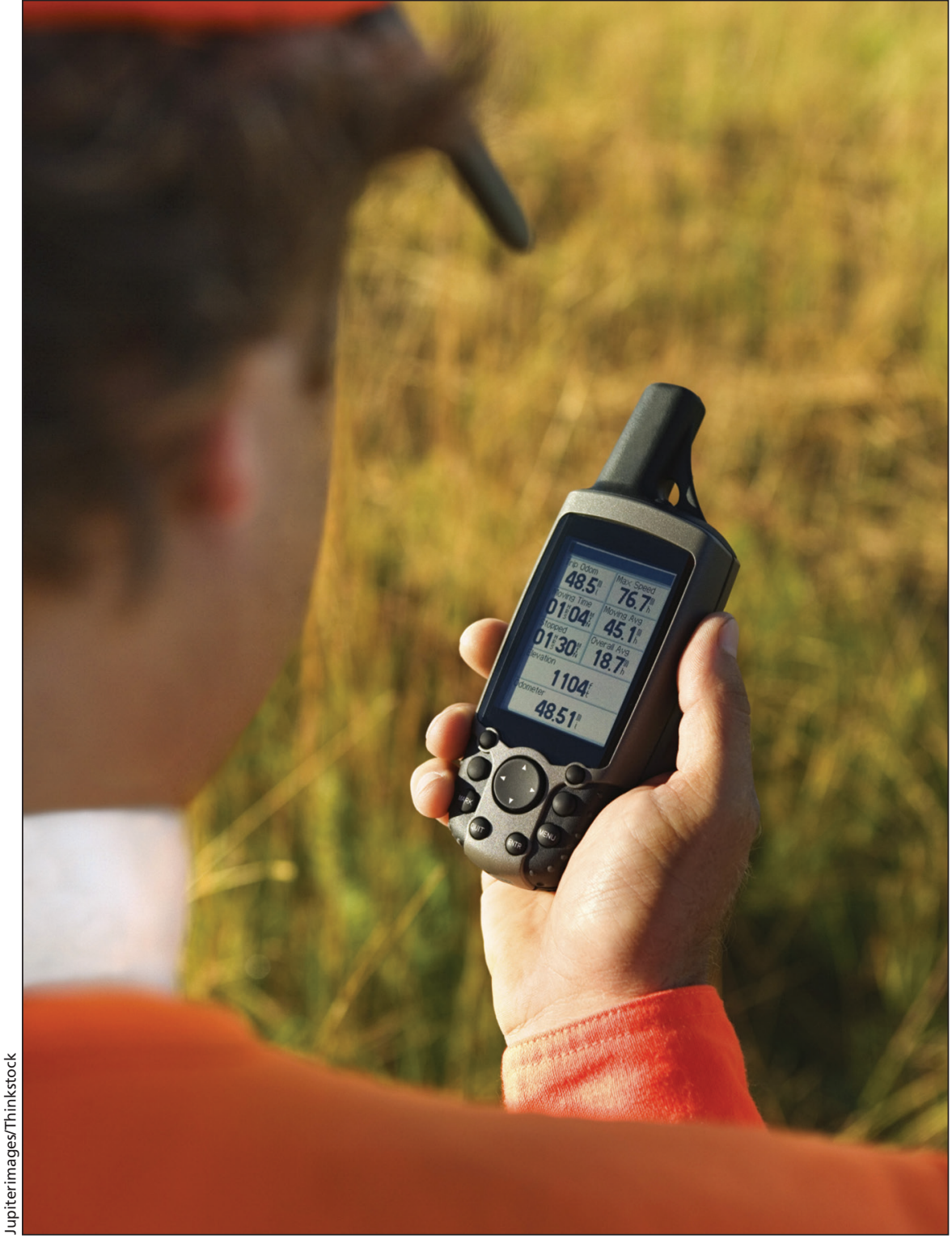

Electronic monitoring of forensic mental health patients is allowed in the United Kingdom and Australia.

bracelet would negatively affect the therapy process and efforts to establish a relationship of trust, as well as community reintegration.

These risks have to be weighed against the public safety offered by electronic monitoring. All three reports commissioned by the health department determined that there was no definitive evidence to confirm a positive connection. "There was no support or specula- tive support that electronic monitoring would enhance public safety," notes Sheila Wildeman, associate director of the Health Law Institute and a coauthor of the legal report.

At present, no jurisdiction in North America uses electronic bracelets to monitor forensic psychiatric patients who are on authorized or unauthorized leave, according to another of the Nova Scotia reports. Britain and Australia, 
however, do have such programs in place. Both were implemented in the wake of serious threats to public safety including a homicide committed when one London patient escaped hospital custody. In the UK, where GPS bracelets can track a patient to within a few yards, the mandatory program was initiated by clinicians and senior managers. In Australia, the program was implemented as a result of a political directive.

Changes made to processes and procedures at the East Coast Forensic Hospital, the only facility in Canada that is both a hospital and correctional facility, also contributed to the government's decision that electronic monitoring is not necessary. Following the homicide that was allegedly committed by a forensic patient, a review of the hospital's community-access privileges was conducted.

Eighteen recommendations were put forward, all of which have been implemented, says Scott. These changes include increased use of a risk assessment process, and a requirement for more patient and staff interaction. As well, community monitors have been put in place. These are people located in the community who personally check on patients absent from the hospital to ascertain they are where they said they would be and are not violating the terms of their release.
Recent changes to the federal Criminal Code in 2014 have also decreased the likelihood of a serious incident occurring while patients are on leave from the forensic hospital. The amended legislation creates a special class of high-risk accused, including those who show a substantial risk of using violence. People in this group are no longer eligible for unescorted leaves in the community.

Ultimately, says Scott, "the key issue is balancing patient rights with safety. We can't mitigate all risk." - donalee Moulton, Halifax, NS

CMAJ 2015. DOI:10.1503/cmaj.109-5024 